\title{
Comparison of MA-g-PP effectiveness through mechanical performance of functionalised graphene reinforced polypropylene
}

\author{
Saravanan Natarajan' (D), Rajasekar Rathanasamy ${ }^{1 *}$ (D), Sathish Kumar Palaniappan² (D), \\ Suresh Velayudham ${ }^{3}$ (D), Hari Bodipatti Subburamamurthy' ${ }^{1}$ (D) and Kaushik Pal ${ }^{4}$ (D) \\ 'Department of Mechanical Engineering, Kongu Engineering College, Erode, Tamil Nadu, India \\ ${ }^{2}$ Department of Mining Engineering, Indian Institute of Technology Kharagpur, West Bengal, India \\ ${ }^{3}$ Department of Mechanical Engineering, Sona College of Technology, Salem, Tamil Nadu, India \\ ${ }^{4}$ Department of Mechanical \& Industrial Engineering, Indian Institute of Technology Roorkee, \\ Uttarakhand, India \\ *rajasekar.cr@gmail.com
}

\begin{abstract}
This work aims in developing carboxyl functionalised graphene based PP nanocomposites by using melt mixing method to enhance the mechanical and thermal properties. Maleic anhydride grafted polypropylene was used as a compatibilizer to achieve better compatibility between the non-polar polymer and polar nanofiller. FTIR study confirms the presence of functional groups at corresponding absorption levels. TEM and SEM image shows the uniform distribution of $\mathrm{COOH}-\mathrm{Gr}$ onto the PP matrix with the addition of MA-g-PP onto it. The tensile strength and young's modulus of PMG5 depicts better improvement of $62 \%$ and $20 \%$ compared to neat sample. The increase in storage modulus of $19.02 \%$ was obtained for PG and $43.48 \%$ for PMG samples. The reduction in $\tan \delta$ peak confirms the minimum heat buildup and as a result, leads to better damping characteristics of the nanofiller incorporated PP matrix.
\end{abstract}

Keywords: functionalised graphene, maleic anhydride grafted polypropylene, polypropylene, scanning electron microscopy, transmission electron microscopy.

How to cite: Natarajan, S., Rathanasamy, R., Palaniappan, S. K., Velayudham, S., Subburamamurthy, H. B., \& Pal, K. (2020). Comparison of MA-g-PP effectiveness through mechanical performance of functionalised graphene reinforced polypropylene. Polimeros: Ciência e Tecnologia, 30(3), e2020035. https://doi.org/10.1590/0104-1428.05620

\section{Introduction}

Polymer nanocomposites are the material wherein nanofillers are reinforced in a polymer matrix. Polypropylene (PP) is a thermoplastic material used in several applications like reusable containers of various types and stationery plastic parts, automotive components, laboratory equipments and polymer banknote ${ }^{[1]}$. PP is a breed of polymer which transforms its phase into liquid when it is heated and when freezing, it turns into a glassy state. Recently researches are being carried out with nanofillers such as exfoliated clay, alumina, silica, graphene, carbon nanofibers, carbon nanotubes, nanocrystalline metals and also nanoscale inorganic fillers or modified fibers ${ }^{[2]}$. Nanofillers enable better dispersal of the fillers into the matrix, outcome as enhancement of properties of base matrix ${ }^{[3,4]}$. Superior interaction of nanofillers with other particles and improvement in properties is because of high surface area of the nanofillers ${ }^{[1]}$. Another effect of the nanofillers is the change in glass transition temperature $\left(T_{\mathrm{g}}\right)$. Both increase and decrease in $T_{\mathrm{g}}$ have been noticed depends on the interaction between the polymer and nanofiller. Some of the nanofillers used are carbon black, nano clay, carbon nanotubes, graphite oxide, graphene, copper nanoparticles

etc. Nanoparticles show improvement in properties at very low loadings. Thus it leads to significant reduction in weight for the same strength, performance and properties.

The present report emphasis on the use of graphene, a carbon based nanofiller. A distinct characteristics of carbon is the wide range of forms that it can assume when two or more atoms bond. Thus the carbon has attracted and continued in the direction to attract, a considerable research and development interest from researchers of all parts of the world ${ }^{[4,5]}$. The carbon usage in nanotechnology is quite promising research area and considerable funding was invested by the government to carbon nanotechnology research.

Pure PP without addition of any reinforcements is not suitable for potential applications. Some of the undesirable properties such as stiffness and rigidity may be enhanced by addition of suitable reinforcements. Though PP finds wide range of applications, its strength is not acceptable. The focus lies on enhancing its strength characteristics. Unfortunately, addition of reinforcements may not have superior adhesive 
property. This research focuses at increasing the strength and adhesive characteristics of PP in order to extent its usage ${ }^{[5]}$.

PP nanocomposites have been synthesized with a variety of nanocomposite like modified calcium carbonate $\left(\mathrm{CaCO}_{3}\right)$, nanoclay, layered silicate and multi walled carbon nanotubes (MWCNT). Derivatives of graphite have also been used as nanofillers. An effort has been made to use $\mathrm{COOH}$ functionalised graphene ( $\mathrm{COOH}-\mathrm{Gr}$ ) as the nanofiller in turn to enhance the thermal property of the PP nanocomposite. Modification of graphene by adding carboxyl or hydroxyl groups on outer periphery of the graphene particles has found to be increases its interaction with polymer matrix ${ }^{[6-8]}$. Functional groups added may be carboxyl, amine or epoxy groups. COOH-Gr is highly polar and PP is nonpolar, mismatch occurs during nanocomposite production. Maleic anhydride grafted polypropylene (MA-g-PP) is the compatibilizer used to further increase the interaction among the fillers and the matrix ${ }^{[9,10]}$. This is possible because of the polar to polar interaction between the compatibilizer and $\mathrm{COOH}-\mathrm{Gr}$. Polymer nanocomposite with graphite oxide derivative graphene material as fillers have made known dramatic improvements in its tensile strength, elastic modulus, thermal behavior and electrical conductivity of the nanocomposite. Enhancements at low loadings have been observed due to large interfacial area and high aspect ratio.

This work aims to prepare PP/functionalised graphene nanocomposite and compare the reinforcing result of $\mathrm{COOH}-\mathrm{Gr}$ on the mechanical and thermal behavior of PP nanocomposite. This study also explains the morphology of prepared nanocomposite and to review the distribution of nanofillers in polymer matrix.

\section{Materials and methods}

\subsection{Materials}

Commercial grade of PP was provided by Reliance Industries Limited, Mumbai, India. MA-g-PP with
8-10 wt.-\% maleic anhydride content was obtained from SIGMA-ALDRICH and the chemical formula for the same is $\left(\mathrm{C}_{3} \mathrm{H}_{6}\right)_{\mathrm{m}}\left(\mathrm{C}_{7} \mathrm{H}_{8} \mathrm{O}_{3}\right) \mathrm{n}$. COOH-functionalised graphene with carboxyl content of $20 \%$ was supplied by United Nanotech Innovations Pvt. Ltd., Bangalore.

\subsection{Methods}

\subsubsection{Melt mixing}

The preparation of polymeric nanocomposite was carried out using melt mixing method ${ }^{[9,1]}$. The mixing operations were done at $160^{\circ} \mathrm{C}$ for a time period of 15 minutes. The speed is constantly maintained $50 \mathrm{rpm}$ for throughout the mixing process. Initially the PP granules were feed in between the two rolls and allowed to mix for 5 minutes, Compatibilizer (MA-g-PP) is added to semisolid state PP content and mixed together for 3 more minutes. Functionalized graphene was poured in between the rolls once after the polymer gets completely melted. The whole blend is mixed for further 7 minutes to attain homogeneous mixing.

\subsubsection{Mixing formulation}

The mixing formulation for preparing the PP nanocomposite is shown in Table 1. "PP" denotes pure polypropylene, "PM" denotes PP with MA-g-PP, "PG" denotes PP with $\mathrm{COOH}-$ Gr and "PMG" denotes PP with COOH-Gr and MA-g-PP.

\subsubsection{Compression molding}

Compression molding is one of the plastic forming process in which a plastic material is placed directly in metal mold and kept in between two hot plates. Polymers softened by the applied heat and pressure to get the shape of the mold. The temperature of $160{ }^{\circ} \mathrm{C}$ and pressure of $0.8 \mathrm{MPa}$ are maintained upto the molding polymer gets cured. Tensile and DMA tests specimens were made from compression molding process. The DMA specimens dimension were $6.4 \mathrm{~cm}$ length $\mathrm{x} 1.27 \mathrm{~cm}$ width $\mathrm{x} 0.32 \mathrm{~cm}$ thick.

Table 1. Samples mixing formulation.

\begin{tabular}{ccccc}
\hline Sl. No. & Sample code & PP (wt. - \%) & MA-g-PP (wt.-\%) & COOH - Gr (wt.- \%) \\
\hline 1. & PP & 100 & - & - \\
2. & PM1 & 97.5 & 2.5 & - \\
3. & PM2 & 95 & 5 & - \\
4. & PM3 & 92.5 & 7.5 & - \\
5. & PM4 & 90 & 10 & - \\
6. & PM5 & 87.5 & 15.5 & - \\
7. & PM6 & 85 & - & 0.5 \\
8. & PG1 & 100 & - & 1 \\
9. & PG2 & - & 1.5 \\
10. & PG3 & 100 & - & 2 \\
11. & PG4 & 100 & - & 2.5 \\
12. & PG5 & 100 & - & 3 \\
13. & PG6 & 2.5 & 0.5 \\
14. & PMG1 & 97.5 & 5 & 1 \\
15. & PMG2 & 95 & 7.5 & 1.5 \\
16. & PMG3 & 92.5 & 10 & 2 \\
17. & PMG4 & 90 & 12.5 & 2.5 \\
18. & PMG5 & 87.5 & 15 & 3 \\
19. & PMG6 & 85 & & \\
\hline
\end{tabular}




\subsubsection{Fourier Transform Infrared Spectroscopy (FTIR)}

The Fourier transform infrared spectroscopy (FTIR) spectrum of graphene and modified graphene has been documented using a NEXUS 870 FTIR (Thermo Nicolet) equipment. The samples were prepared by making palate with $\mathrm{KBr}$ for characterization ${ }^{[12,13]}$. The signal resolution was $2 \mathrm{~cm}^{-1}$ and a minimum of 64 scans were within the range of $4000-500 \mathrm{~cm}^{-1}$.

\subsubsection{Transmission electron microscopy (TEM)}

Transmission electron microscopy (TEM) imaging was carried out using JEM-2100 (JEOL JEM Co.) electron microscope. Dispersion morphology of composite samples are microtomed as very thin slices of $80 \mathrm{~nm}$ approximately by means of ultra microtome with a diamond knife and the temperature of samples were retain at $-80^{\circ} \mathrm{C}$ using liquid nitrogen.

\subsubsection{Mechanical properties}

Dumb-bell shaped samples were made from compression molding process. The investigations were done under ambient condition with a universal testing machine (Hounsfield H10KS), the specimens were prepared for ASTM D 41206 and ASTM D 624-00(2007) standards. Tensile strength and Modulus of elasticity were measured at ambient temperature. The primary length of the specimens was $40 \mathrm{~mm}$ and $50 \mathrm{~mm} /$ min speed was maintained for jaw separation.

\subsubsection{Dynamic Mechanical Analysis (DMA)}

The TA Instruments DMA 2980 model instrument is used to characterize the materials mechanical behavior at different temperatures. The dynamic properties of the samples with dimensions $35 \mathrm{~mm}$ length, $12 \mathrm{~mm}$ width and $3 \mathrm{~mm}$ thick was studied at constant frequency mode with $1 \mathrm{~Hz}$ frequency ${ }^{[14]}$. The samples were heated at a rate of $3^{\circ} \mathrm{C} /$ min to the temperature range of $30^{\circ} \mathrm{C}$ to $130^{\circ} \mathrm{C}$.

\subsubsection{Scanning electron microscopy (SEM)}

The tensile fractured face of the specimens were imaged with scanning electron microscope (Model: JSM-5800 of JEOL Co., Acceleration voltage: $20 \mathrm{kV}$, Coating type: gold) at 1000 times zooming ${ }^{[15]}$. The surface morphology of fabricated specimens can also be studied using scanning electron microscopy ${ }^{[1,5,16]}$.

\section{Results and discussions}

\subsection{FTIR}

The existence of functional groups $\mathrm{O}-\mathrm{H}$ and $\mathrm{C}-\mathrm{O}$ are confirmed from FTIR (Figure 1) results. This is arrived by the identification of peaks at 1276,1710 and $3432 \mathrm{~cm}^{-1}$ which match up to $\mathrm{C}-\mathrm{O}$ stretching, $\mathrm{C}=\mathrm{O}$ stretching and $\mathrm{O}-\mathrm{H}$ stretching correspondingly. Hence the sample was confirmed to be $\mathrm{COOH}$ modified graphene ${ }^{[3,13,17]}$. The covalent bonds of molecules are like springs that are stiff but stretch and bend. At normal temperatures these bond vibrate in accordance with their electronic states.

The stretching takes place during the absorption of infrared rays when these bonds experience a transition between the energy levels induced by photons of appropriate energy.
Each functional group has corresponding absorption levels which are identified from the FTIR results.

\subsection{TEM}

TEM image of $2 \mathrm{wt.}-\%$ of functionalised graphene dispersed in PP matrix is revealed in Figure 2. The agglomeration of $\mathrm{COOH}-\mathrm{Gr}$ in the matrix is observed in Figure 2. However, Figure 3 illustrates the TEM image of polymer matrix with $2 \mathrm{wt} . \mathrm{\%} \%$ of functionalised graphene and the addition of $10 \mathrm{wt} . \mathrm{-} \%$ compatibilizer onto it. It proves the successful exfoliation of single layer graphene which gets uniformly distributed in the polymer matrix ${ }^{[9,18]}$, this is because of the addition of compatibilizer which improved the bonding between matrix and the filler. However, Figure 3 reveals that addition of compatibilizer shows better dispersion of nanoparticles compared to Figure 2.

\subsection{Mechanical properties}

Mechanical properties were studied for pure and functionalised graphene filled PP matrix is shows in the Figure 4. For the uncompatibilized system (PG1 to PG4) the tensile strength gradually enhance with increase in nanofiller content. The tensile strength values of the samples PG1, PG2, PG3 and PG4 increased by $18 \%, 22 \%, 36 \%$ and $47 \%$ respectively when compared to pure PP.

The maximum increase in tensile strength was achieved for PG4 (29.4 MPa for $2.0 \mathrm{wt} . \mathrm{-} \%$ of graphene). Further loading of COOH-Gr in the PP matrix (PG5 and PG6) shows drop in tensile strength compared to PG4. The increase in addition of graphene may lead to agglomeration of nanoparticles in the PP matrix ${ }^{[3,19]}$. Hence the tensile strength starts to decrease.

The blend PM1, PM2, PM3, PM4, PM5 and PM6 shows a slow gradual improvement on tensile strength when compared with pure polymer.

The compatibilized system shows considerable enhancement in tensile strength compared to uncompatabilized and pure systems. The percentage enhance in tensile strength for the samples PMG1, PMG2, PMG3, PMG4 and PMG5 compared

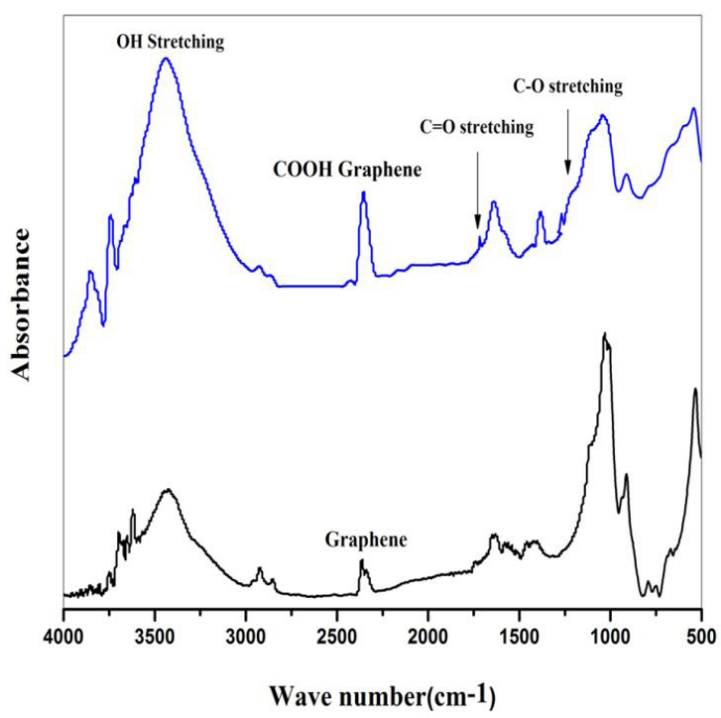

Figure 1. FTIR spectrum of graphene and $\mathrm{COOH}$ modified graphene. 


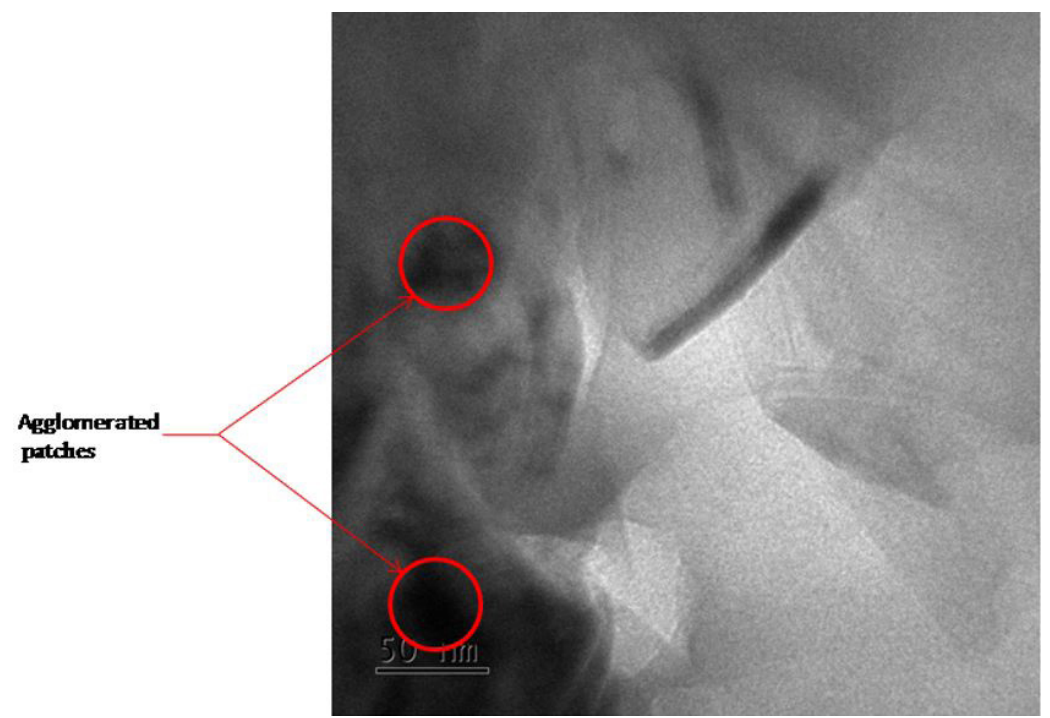

Figure 2. TEM image of $\mathrm{PP}+2$ wt. \% of $\mathrm{COOH}-\mathrm{Gr}$.

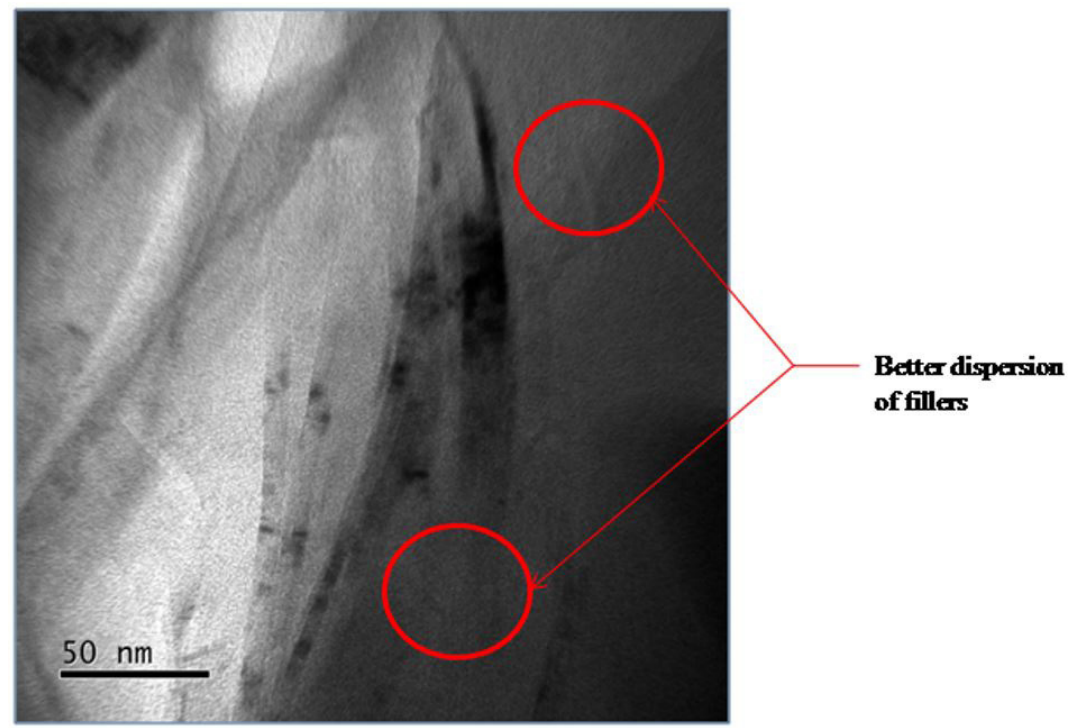

Figure 3. TEM image of compatabilized PP +2 wt.- $\%$ of modified graphene.

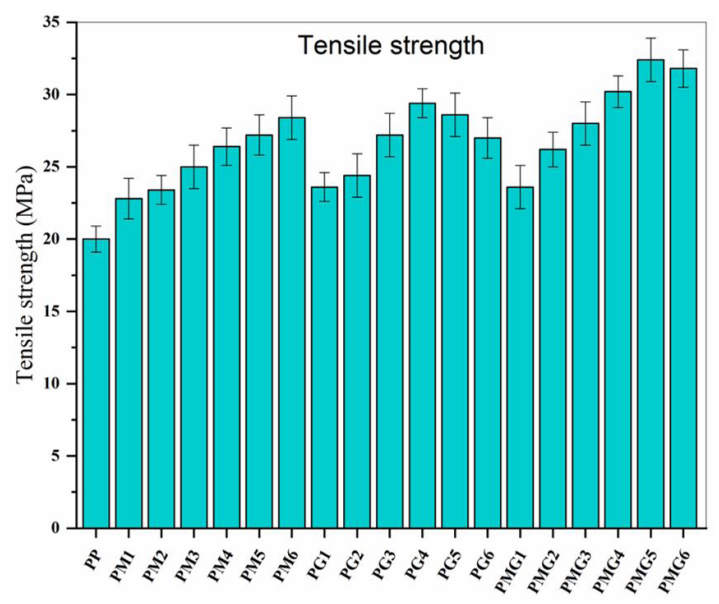

Figure 4. Tensile strength of PP, PG and PMG. to pure PP are $18 \%, 31 \%, 40 \%, 51 \%$ and $62 \%$ respectively. The maximum tensile strength of $32.4 \mathrm{MPa}$ was achieved for the sample PMG5. The same shows $62 \%$ enhancement in tensile strength match up to pure PP. The presence of compatibilizer enhances the dispersal of graphene in the base PP matrix ${ }^{[9,10,20]}$. However with increase in filler content beyond 5 wt.- $\%$ for PMG5, the tensile strength starts to decrease.

For both uncompatibilized and compatibilized system the elastic modulus gradually increases with increase in addition of graphene in the PP matrix. The Young's modulus for blend PM1, PM2, PM3, PM4 and PM5 increases upto $6 \%$ compared to pure polymer, later on decreases for PM6. For the uncompatibilized system $5 \%, 7 \%, 8 \%$, and $10 \%$ increase of modulus was obtained for the samples PG1, PG2, PG3 and PG4 respectively. From Figure 5, on further adding of COOH-Gr (2.5 wt.- $\%$ and 3 wt.-\%) decreases the elastic modulus of PG5 and PG6. Similarly for the compatibilized system shows $10 \%, 12 \%, 13 \%, 18 \%$ and 


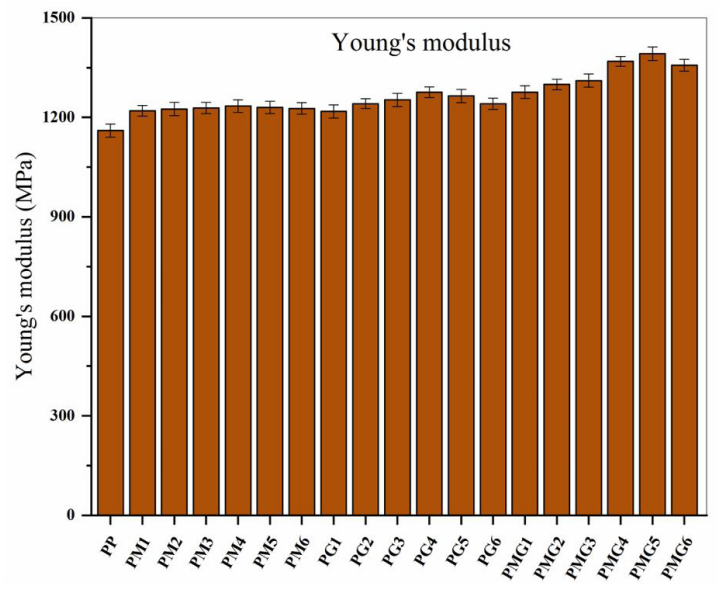

Figure 5. Young's modulus of PP, PG and PMG.

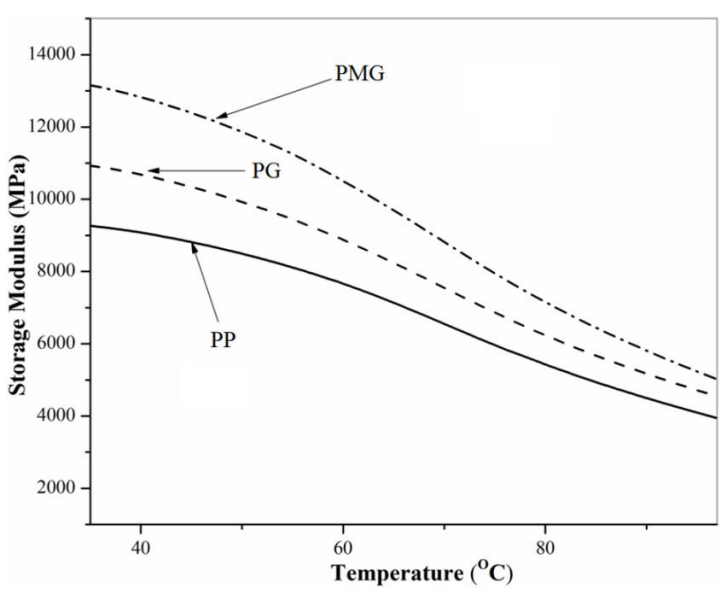

Figure 6. Storage modulus for PP, PG and PMG.

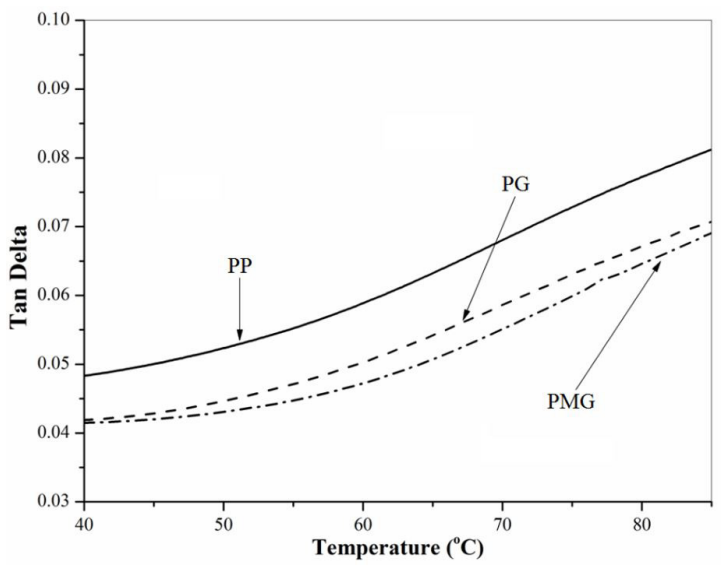

Figure 7. Tan $\delta$ peak for PP, PG and PMG.

$20 \%$ increase of modulus for the samples PMG1, PMG2, PMG3, PMG4 and PMG5 respectively. On further addition of COOH-Gr (3 wt.-\%) decreases the modulus of PMG6. At last, this overall increase of mechanical properties is due to homogeneity in mixing and better dispersion of functionalised fillers in matrix.

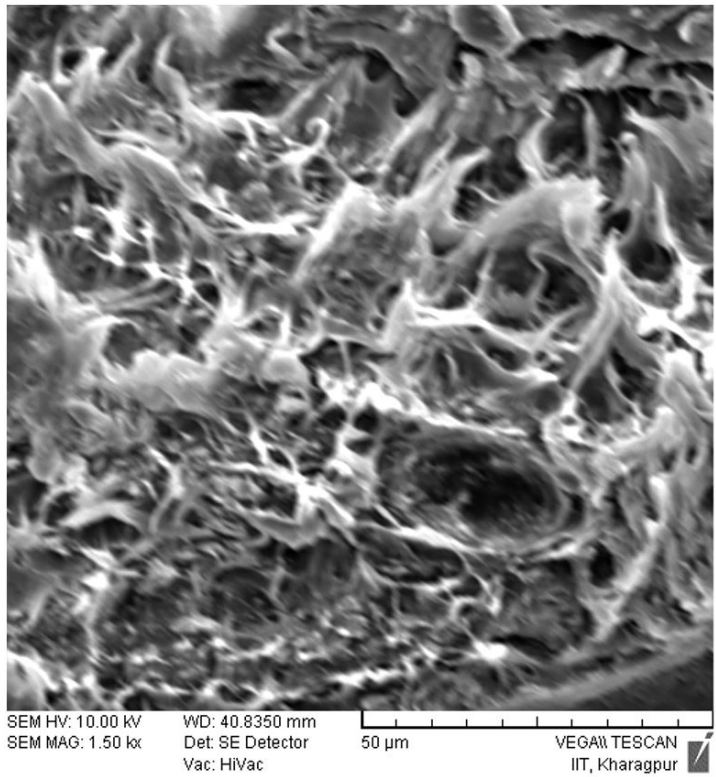

Figure 8. SEM image of fracture surface with $2.5 \mathrm{wt} .-\% \mathrm{COOH}-$ $\mathrm{Gr}+\mathrm{MA}-\mathrm{g}-\mathrm{PP}+\mathrm{PP}$.

\subsection{DMA studies}

Figure 6 characterizes the temperature dependence of storage modulus (E') of nanocomposite. The nanocomposite containing modified graphene showed a development in storage modulus on compared with PP and PG. An increase of $19.02 \%$ was observed for PP and graphene nanocomposite compared to pure PP.

Several studies ${ }^{[21,22]}$ have confirmed that inclusion of graphene (particles, sheets) can boost the thermal behavior of the polymer to different degree. Some studies ${ }^{[23,24]}$ exposed that incorporation of functionalized graphene (particles, sheets) accelerates the thermal degradation of polymer in inert condition. The enhancement in storage modulus is additional evidence for the compatibilized nanocomposites. The compatibilized $\mathrm{COOH}-\mathrm{Gr}$ system showed an increase of $43.48 \%$ in storage modulus compared to PP.

With increase in filler loading the peak intensity of $\tan \delta$ consecutively decreases. This may be due to better reinforcing effectiveness of the filler with the PP matrix. Figure 7 signifies the tan $\delta$ of PP, PG and PMG. The reduction in $\tan \delta$ peak confirms the minimum heat buildup and as a result, leads to better damping characteristics of the nanofiller incorporated PP matrix.

\subsection{Morphological study}

The polar nature of $\mathrm{COOH}-\mathrm{Gr}$ will not be compatible upon mixing in bulk non-polar PP matrix. In order to avoid the compatibility mismatch, a polar compatibilizer MA-g-PP derived from base $\mathrm{PP}$ is used as a medium to attain effective reinforcement of $\mathrm{COOH}-\mathrm{Gr}$ in base matrix.

However, PMG5 sample shows better tensile strength and Young's modulus. So, the SEM study of PMG5 sample has also been done to add more proof of the obtained results. SEM image (Figure 8) shows a fibrillated morphological texture, which proves the enhancement in compatibility between polar $\mathrm{COOH}-\mathrm{Gr}$ and non-polar PP matrix by introducing MA-g-PP as compatibilizer ${ }^{[18,20]}$. 


\section{Conclusion}

In summary, PP nanocomposite was prepared by incorporating $\mathrm{COOH}$ functionalised graphene to investigate the enrichment of mechanical and thermal stability of PP. FTIR results confirm the presence of functional groups in modified graphene by corresponding absorption levels. TEM image justifies the successful exfoliation of single layer graphene, uniformly distributed in PP matrix. Significant enhancement in the mechanical properties and dynamic mechanical properties was achieved for compatibilized PP nanocomposites compared to uncompatibilized and pure system. The surface morphology shows a fibrillated morphological texture, which proves the enhancement in compatibility between polar $\mathrm{COOH}-\mathrm{Gr}$ and non-polar PP matrix by introducing MA-g-PP as compatibilizer. As of the results, it confirms that addition of nanofiller reinforcement into the polymer matrix, compatibility match between the fillers and base matrix plays a role in varying the properties of the polymer.

\section{References}

1. Qiu, F., Yin, X., \& Qu, J. P. (2019). Formation of polypropylene/functional graphene oxide nanocomposites with Different FGs loading in elongation flow condition. Polymer Engineering and Science, 59(4), 830-837. http:// dx.doi.org/10.1002/pen.25017.

2. Raji, M., Mekhzoum, M. E. M., Rodrigue, D., Qaiss, A., \& Bouhfid, R. (2018). Effect of silane functionalization on properties of polypropylene/clay nanocomposites. Composites. Part B, Engineering, 146, 106-115. http:// dx.doi.org/10.1016/j.compositesb.2018.04.013.

3. Saravanan, N., Rajasekar, R., Mahalakshmi, S., Sathishkumar, T., Sasikumar, K., \& Sahoo, S. (2014). Graphene and modified graphene-based polymer nanocomposites-a review. Journal of Reinforced Plastics and Composites, 33(12), 1158-1170. http://dx.doi.org/10.1177/0731684414524847.

4. Ovid'Ko, I. (2013). Enhanced mechanical properties of polymer-matrix nanocomposites reinforced by graphene inclusions: a review. Reviews on Advanced Materials Science, 34(1), 19-25. Retrieved in 2020, June 17, from http://www. ipme.ru/e-journals/RAMS/no_13413/03_13413_ovidko.pdf

5. Maheshkumar, K., Krishnamurthy, K., Sathish kumar, P., Sahoo, S., Uddin, E., Pal, S., \& Rajasekar, R. (2014). Research updates on graphene oxide-based polymeric nanocomposites. Polymer Composites, 35(12), 2297-2310. http://dx.doi.org/10.1002/pc.22899.

6. Bai, H., Li, C., \& Shi, G. (2011). Functional composite materials based on chemically converted graphene. Advanced Materials, 23(9), 1089-1115. http://dx.doi.org/10.1002/ adma.201003753. PMid:21360763.

7. Lin, Y., Jin, J., \& Song, M. (2011). Preparation and characterisation of covalent polymer functionalized graphene oxide. Journal of Materials Chemistry, 21(10), 3455-3461. http://dx.doi.org/10.1039/C0JM01859G.

8. Ramanathan, T., Abdala, A., Stankovich, S., Dikin, D., Herrera-Alonso, M., Piner, R. D., Adamson, D., Schniepp, H., Chen, X., Ruoff, R., Nguyen, S. T., Aksay, I. A., Prud'Homme, R. K., \& Brinson, L. C. (2008). Functionalized graphene sheets for polymer nanocomposites. Nature Nanotechnology, 3(6), 327-331. http://dx.doi.org/10.1038/ nnano.2008.96. PMid:18654541.

9. Modesti, M., Lorenzetti, A., Bon, D., \& Besco, S. (2005). Effect of processing conditions on morphology and mechanical properties of compatibilized polypropylene nanocomposites. Polymer, 46(23), 10237-10245. http:// dx.doi.org/10.1016/j.polymer.2005.08.035.

10. Mohaiyiddin, M. S., Lin, O. H., Akil, H. M., Yee, T. G., Adik, N. N. A. N., \& Villagracia, A. R. (2016). Effects of polypropylene methyl polyhedral oligomeric silsesquioxanes and polypropylene-grafted maleic anhydride compatibilizers on the properties of palm kernel shell reinforced polypropylene biocomposites. Polímeros: Ciência e Tecnologia, 26(3), 228-235. http://dx.doi.org/10.1590/0104-1428.2038.

11. Kalaitzidou, K., Fukushima, H., \& Drzal, L. T. (2007). Mechanical properties and morphological characterization of exfoliated graphite-polypropylene nanocomposites. Composites. Part A, Applied Science and Manufacturing, 38(7), 16751682. http://dx.doi.org/10.1016/j.compositesa.2007.02.003.

12. Sahoo, S., Karthikeyan, G., Nayak, G., \& Das, C. K. (2012). Modified graphene/polyaniline nanocomposites for supercapacitor application. Macromolecular Research, 20(4), 415-421. http://dx.doi.org/10.1007/s13233-012-0042-1.

13. Rajasekar, R., Kim, N. H., Jung, D., Kuila, T., Lim, J. K., Park, M. J., \& Lee, J. H. (2013). Electrostatically assembled layer-by-layer composites containing graphene oxide for enhanced hydrogen gas barrier application. Composites Science and Technology, 89, 167-174. http://dx.doi. org/10.1016/j.compscitech.2013.10.004.

14. Lei, S., Hoa, S. V., \& Ton-That, M.-T. (2006). Effect of clay types on the processing and properties of polypropylene nanocomposites. Composites Science and Technology, 66(10), 1274-1279. http://dx.doi.org/10.1016/j. compscitech.2005.09.012.

15. Pal, K., Rajasekar, R., Kang, D. J., Zhang, Z. X., Pal, S. K., Das, C. K., \& Kim, J. K. (2010). Effect of filler and urethane rubber on NR/BR with nanosilica: morphology and wear. Journal of Thermoplastic Composite Materials, 23(5), 717-739. http://dx.doi.org/10.1177/0892705709355234.

16. Nikje, M. M. A., Moghaddam, S. T., \& Noruzian, M. (2016). Preparation of novel magnetic polyurethane foam nanocomposites by using core-shell nanoparticles. Polímeros: Ciência e Tecnologia, 26(4), 297-303. http:// dx.doi.org/10.1590/0104-1428.2193.

17. Choi, E.-Y., Han, T. H., Hong, J., Kim, J. E., Lee, S. H., Kim, H. W., \& Kim, S. O. (2010). Noncovalent functionalization of graphene with end-functional polymers. Journal of Materials Chemistry, 20(10), 1907-1912. http://dx.doi. org/10.1039/b919074k.

18. Song, P., Cao, Z., Cai, Y., Zhao, L., Fang, Z., \& Fu, S. (2011). Fabrication of exfoliated graphene-based polypropylene nanocomposites with enhanced mechanical and thermal properties. Polymer, 52(18), 4001-4010. http://dx.doi. org/10.1016/j.polymer.2011.06.045.

19. Simanke, A. G., Azeredo, A. P., Lemos, C., \& Mauler, R. S. (2016). Influence of nucleating agent on the crystallization kinetics and morphology of polypropylene. Polimeros: Ciência e Tecnologia, 26(2), 152-160. http://dx.doi. org/10.1590/0104-1428.2053.

20. Kumar, K. V. M., Krishnamurthy, K., Rajasekar, R., Kumar, P. S., Pal, K., \& Nayak, G. C. (2019). Influence of graphene oxide on the static and dynamic mechanical behavior of compatibilized polypropylene nanocomposites. Materials Testing, 61(10), 986-990. http://dx.doi.org/10.3139/120.111411.

21. Liang, J., Huang, Y., Zhang, L., Wang, Y., Ma, Y., Guo, T., \& Chen, Y. (2009). Molecular-level dispersion of graphene into poly (vinyl alcohol) and effective reinforcement of their nanocomposites. Advanced Functional Materials, 19(14), 2297-2302. http://dx.doi.org/10.1002/adfm.200801776. 
22. Xu, Y., Hong, W., Bai, H., Li, C., \& Shi, G. (2009). Strong and ductile poly (vinyl alcohol)/graphene oxide composite films with a layered structure. Carbon, 47(15), 3538-3543. http://dx.doi.org/10.1016/j.carbon.2009.08.022.

23. Lee, Y. R., Raghu, A. V., Jeong, H. M., \& Kim, B. K. (2009). Properties of waterborne polyurethane/functionalized graphene sheet nanocomposites prepared by an in situ method. Macromolecular Chemistry and Physics, 210(15), 1247-1254. http://dx.doi.org/10.1002/macp.200900157.
24. Raghu, A. V., Lee, Y. R., Jeong, H. M., \& Shin, C. M. (2008). Preparation and physical properties of waterborne polyurethane/functionalized graphene sheet nanocomposites. Macromolecular Chemistry and Physics, 209(24), 2487. 2493. http://dx.doi.org/10.1002/macp.200800395.

Received: June 17, 2020 Revised: Aug. 07, 2020 Accepted: Oct. 13, 2020 